\title{
A MODIFICATION OF THE GREY BACKGROUND TEST
}

\author{
BY \\ F. A. Williamson-Noble \\ LONDON
}

A CERTAIN amount of irregular astigmatism is almost universal and is a frequent cause of difficulty in using the grey background test in astigmatism. It is usual when using this test for the patient to be made, by means of spherical lenses, artificially

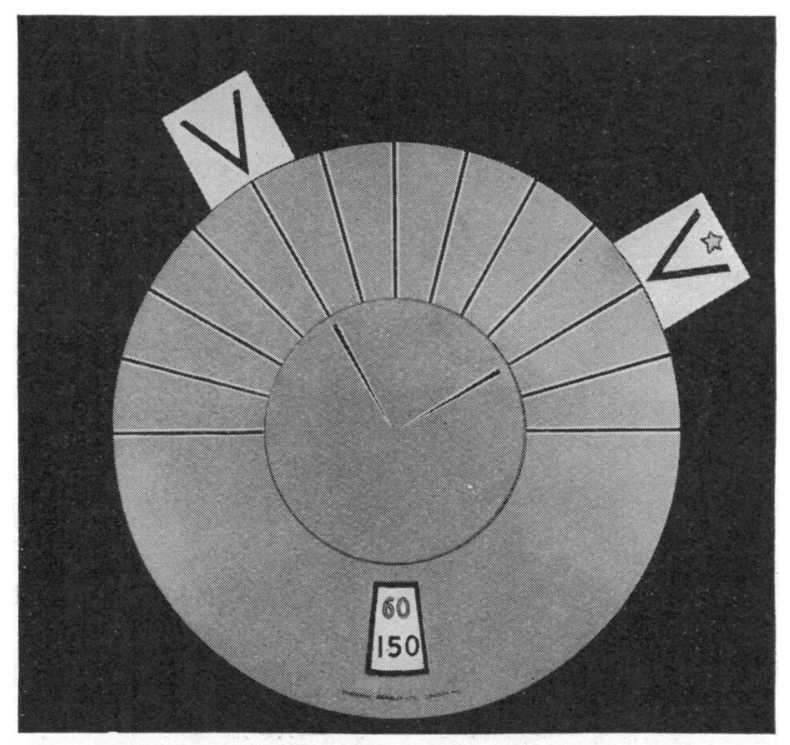

myopic, so that one group of lines approximating to the principal axis of the astigmatism stands out more clearly than the others. One line of this group may then be further emphasized by means of the Maddox "V." A minus cylinder is then inserted along the axis at right angles to the clearest line and the strength of the cylinder, is varied until the line is as clear as that indicated by the "V." In cases where there is some irregular astigmatism, however, it has frequently been found that after inserting a minus cylinder of the required strength, one of the lines other than that indicated by the " $\mathrm{V}$ " springs into prominence, and diverts the patient's attention from the main feature of the Test which, of 
course, is to equalize the refraction of the two axes in which the astigmatism is most marked.

A modification has therefore been introduced which consists in a second " $\mathrm{V}$ " and the object of this is to enable the surgeon to call the patient's attention to two lines at right angles to each other, and to work on these two lines only.

By this means one can avoid much of the confusion that arises from the answers of patients with irregular astigmatism. The method of using the new test is to render the patient sufficiently myopic in the usual way so that only one or possibly two or three lines are left clear on the chart. If these lines are on the right side, the " $\mathrm{V}$ " with the red star is moved until it joins at the clearest line, if on the left side, the other " $V$ " is used. In the former case a red number on the indicator below the fan will notify the axis at which the correcting minus cylinder should be placed, while in the latter case a black number will do so. Cylinders are then inserted until the two lines at right angles to each other are of equal density, other lines on the chart being entirely ignored. By this means a considerable saving of time is effected, and the patient is able to say at once which line is the clearer, by naming the " $\mathrm{V}$ " which points to the line: that with or without the "star."

\title{
ANNOTATION
}

\section{Mediaeval Ophthalmic Treatment in use To day}

\author{
" Excellent herbs had our fathers of old- \\ Excellent herbs to ease their pain- \\ Alexanders and Marygold, \\ Eyebright, Orris, and Elecampane, \\ Basil, Rocket, Valerian, Rue, \\ (Almost singing themselves they run) \\ Vervain, Dittany, Call-me-to-you- \\ Cowslip, Melilot, Rose of the Sun, \\ Anything green that grew out of the mould \\ Was an excellent herb to our fathers of old."
}

For the past eighteen months a man, aged 80 years, has attended our out-patient department with a mature cataract on one side, and an acuity of $6 / 9$ on the other, after correction of half-a-dioptre of hypermetropia. The good eye has a single streak of opacity, downwards and inwards. Three months ago he said that his sight was worse, and an acuity of $6 ! 12$ was all that could be obtained. When seen, at the end of June, he was in a great state of excitement because his vision had improved, as he said, through using 